\title{
Research Update on Findings from the USM Campus Climate Survey: Results Related to LGBTQ Students
}

A brief report by:

Kamden K. Strunk, Ph.D. \& Joy Suggs, M.A.

This report is intended as an update on findings from the Fall 2014 USM Campus Climate Survey with specific emphasis on results related to LBGTQ Students.

Research Initiative on Social Justice and Equity (RISE)

Department of Educational Studies and Research

College of Education and Psychology

The University of Southern Mississippi

November, 2014

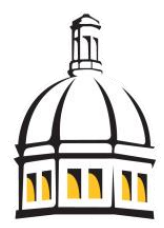

THE UNIVERS I T Y OF

SOUTHERN

MISS IS S I P P I.

COLLEGE OF EDUCATION

AND PSYCHOLOGY

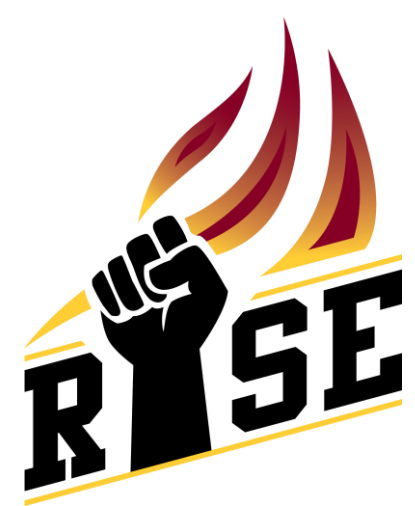




\section{Contents}

Executive Summary ........................................................................................................ 1

Research Update on Findings from the USM Campus Climate Survey:................................... 2

Results Related to LGBTQ Students ............................................................................ 2

LGBTQ Students on College Campuses: Bias, Discrimination, and Educational Outcomes ........ 2

The USM Campus Climate Survey..................................................................................... 3

Victimization of LGBTQ Students on the USM Campus ................................................... 4

Mean Scores for Comfort in Campus Social Life by LGBTQ Grouping ................................ 4

Mean Scores for Disparaging Comments by Staff by Item by LGBTQ Grouping .................... 5

Percent Hearing Disparaging Remarks by Staff per Identity Category ................................... 6

Mean Scores for Disparaging Comments by Administrators by Item by LGBTQ Grouping ..... 6

Percent Hearing Disparaging Remarks by Administrators per Identity Category ................... 7

Mean Scores on Disparaging Comments by Students by Item by LGBTQ Grouping ............... 7

Percent Hearing Disparaging Remarks by Students per Identity Category ............................. 8

Mean Scores on Frequency Negative Comments Heard by Location by LGBTQ Grouping ..... 9

Mean Scores on Threatening Behavior by Item by LGBTQ Grouping .................................. 10

Percent Witnessing Threatening Behavior Often per Identity Category ................................. 11

LGBTQ Students' Views about Campus ............................................................................... 11

Mean Scores for Perception of Campus by Item by LGBTQ Grouping ................................. 12

Mean Scores of USM as Supportive by Item by LGBTQ Grouping ...................................... 13

Percent Disagreeing Whether USM is Supportive per Identity Category ............................... 13

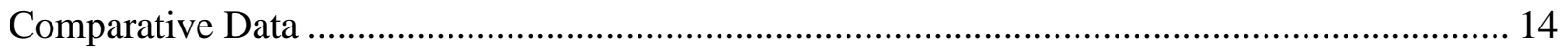

Comparison to Other Universities in the Region and Nation .............................................. 14

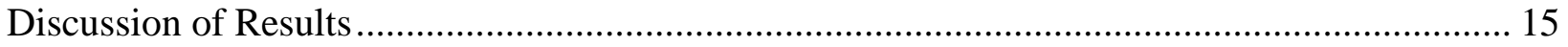

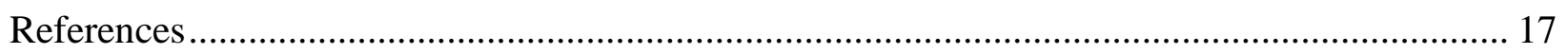




\section{Executive Summary}

LGBTQ students nationally experience bias, discrimination, bullying, harassment, and assault on college campuses. The effects of these negative experiences are known. They can lead to depression, suicidal ideation, lowered earning potential, and a range of other negative outcomes. Also known are the effects of diversity on a college campus. These outcomes are positive for all members of the campus community. This is why it is incumbent on universities to provide safe, inclusive, and diverse campus communities.

The present results make clear that LGBTQ students at USM do not find themselves subject to a supportive and inclusive environment. They are almost twice as likely to become the victim of assault or harassment on campus as their counterparts. They report hearing negative comments from staff, administrators, and other students more often than their counterparts. They witness threatening behavior more often, particularly with regard to sexual orientation and gender identity. That experience isn't unique to LGBTQ students, though. Across all students sampled, 1 in 5 report witnessing threatening behavior on the basis of sexual orientation and gender identity at least somewhat often on the USM campus. Although nearly 4 in 10 students surveyed agreed that a diverse and inclusive campus environment was a factor in deciding which college to attend, LGBTQ students surveyed were less likely to find the USM campus inclusive and committed to diversity.

These results present a clear picture of a challenge and an opportunity. The challenge is to serve the university's LGBTQ students and create an inclusive campus environment despite budget shortfalls and a difficult political/cultural environment in Mississippi for LGBTQ issues. The opportunity is that there is already much work going on at USM to create just such an environment, and that diversity and inclusion may lead to increases in recruitment and retention, particularly among LGBTQ students.

Note. This report is only focused on the LGBTQ relevant data from the USM Campus Climate Survey. A more thorough report is forthcoming in Spring 2015. 


\section{Research Update on Findings from the USM Campus Climate Survey: Results Related to LGBTQ Students}

The purpose of this brief report is to describe the current results of the 2014-2015 Campus Climate survey conducted at The University of Southern Mississippi as they relate to lesbian, gay, bisexual, trans*, and queer (LGBTQ) students. We begin by describing the importance of this issue and how it relates to the overall health of a college campus. We then describe the results of the Campus Climate Survey with regards to victimization of LGBTQ students, their experiences on the USM campus, and their perceptions of the campus. Finally, we discuss some of the best practices from the research literature and how they apply to the results of the Campus Climate Survey.

\section{LGBTQ Students on College Campuses: Bias, Discrimination, and Educational Outcomes}

Bias against LGBT individuals occurs in schools and colleges, and has been documented in the research literature as well as annual surveys. Students report biased language and acts on the part of other students and faculty at the college level (Rankin, et al., 2010). Even in graduate education, students report experiences with stigmatization and bias (Hylton, 2006). In the college admissions process, LGBT students may be more closely scrutinized and even discriminated against due to difference (Strunk \& Bailey, 2014). Furthermore, in these settings, a sense of institutionalized bias exists (Ferfolja, 2007), and even faculty who espouse nondiscrimination as a value tend not to speak up or even actively participate in discrimination and bias (Norris, 1992).

In Mississippi, these issues may be particularly pronounced. Mississippi has approximately 78,000 self-identified LGBTQ citizens, yet they face continued bias, discrimination, and harassment, based on available data. In the state, $54 \%$ of those living in rural settings and $37 \%$ of those living in more urban settings report having experienced workplace harassment (HRC, 2014). About 42\% report experiencing bullying in high school related to being LGBT-identified, with about one in three reporting experiencing harassment on at least a weekly basis. About $25 \%$ have experienced harassment from a public servant such as a police officer. For LGBT Mississippians, bias and discrimination appear to be real and pervasive components of their experience in the state.

These, experiences of discrimination and bias are associated with lowered psychological well-being (Doyle \& Molix, 2014). In schools, bullying is associated with lower educational 
outcomes (Aragon, Poteat, Espelage, \& Koenig, 2014) and lower self-esteem (Kosciw, Palmer, Kull, \& Gretak, 2013). Not only is experiencing bias and discrimination at school associated with poor educational outcomes, it influences later life outcome as well. Those who report having been the subject of anti-LGBT harassment in school are more likely to experience depression, suicidal thoughts, and substance abuse problems (Russell, et al., 2011). These experiences are also associated with economic harms - particularly lower income (Klawitter, 2011). LGBT individuals are more likely to contemplate suicide than others (Irwin \& Austin, 2013), and their experiences with discrimination and bias are a possible explanation for this difference. Although nationally LGBT individuals are more likely to contemplate or attempt suicide, this is particularly true in the South, where $40 \%$ had seriously considered suicide and $15 \%$ had attempted suicide in a recent study (Irwin \& Austin, 2013). Feelings of social isolation and other effects of discrimination appear to be particularly strong in Southern and rural areas (Swank, Frost, \& Fahs, 2012). Some negative outcomes associated with experiencing discrimination and bias may be mitigated by self-disclosure (Morman, Schrodt, \& Tornes, 2013) and positive institutional support (Kosciw, et al., 2013).

In the present report, we outline the ways in which data from the USM Campus Climate Survey show areas in which USM provides this kind of positive institutional support, and ways in which the institution can find room to improve services to LGBTQ students so as to improve psychological, educational, and economic outcomes for those students who are LGBTQ students, and for all who live in the state.

\section{The USM Campus Climate Survey}

The USM Campus Climate survey involved an online questionnaire that was emailed to all actively enrolled students on the Hattiesburg and Gulf Park campuses. Of those, 1162 completed the questionnaire with sufficient data to allow analyses (after remove data that were missing, but not at random). Of those who responded, $9 \%(n=105)$ identified as LGBTQ. Further demographic information is available in the full USM Campus Climate Survey Report, to be released in Spring 2015, along with a copy of the survey instrument. In order to assess differences between LGBTQ students and other students, we used a number of methods.

Because LGBTQ students are few in number compared to the rest of the sample, we utilized two methods to assess differences in order to cross-validate results. First, we used a randomly sampled 200 students who did not identify as LGBTQ students as a comparison group 
for the LGBTQ sample and conducted independent samples $t$-tests. We adjusted for Type I error using the Sidak-Bonferonni procedure. Then, we used the entire sample and conducted MannWhitney $U$ tests to ensure that we would achieve statistical significance in both conditions prior to reporting any result in this report. The exception to this procedure is with victimization data, which are categorical, so a chi-square analysis was used on the entire sample.

\section{Victimization of LGBTQ Students on the USM Campus}

We began by analyzing victimization data. All participants responded as to whether they had ever personally experienced harassment or assault while at USM. Among the entire sample, $10.4 \%$ ( $n=132$ ) indicated they had experienced harassment or assault. However, among LGBTQ students, this number was $15.8 \%$, compared with $9.6 \%$ in those who did not identify as LGBTQ. Using a chi-square analysis, we found that there was a statistically significant dependency between LBGTQ status and victimization $\left(\chi^{2}=6.47, p=.011\right)$, with LGBTQ students overrepresented in the victimized category $(S R=2.3)$. It is worth noting that the type of harassment and assault was not significantly different between LGBTQ students and other students, only the frequency of victimization. This indicates that the disparity in rates of victimization is statistically significant, and that on the USM campus, LGBTQ students are more likely to find themselves subject to harassment and assault than others.

\section{Campus Experiences for LGBTQ Students}

We found significant differences between LGBTQ students and other students on a number of items related to the campus experience. For example, LGBT students were less comfortable, on average, participating in campus life than their counterparts $\left(t_{315}=-3.09, p=\right.$ $\left..002, \omega^{2}=.03 ; Z=-4.39, p<.001\right) .42 .5 \%$ of LGBTQ students rated on the "disagree" side of the scale for this item, compared with only $29.2 \%$ of others.

\section{Mean Scores for Comfort in Campus Social Life by LGBTQ Grouping}

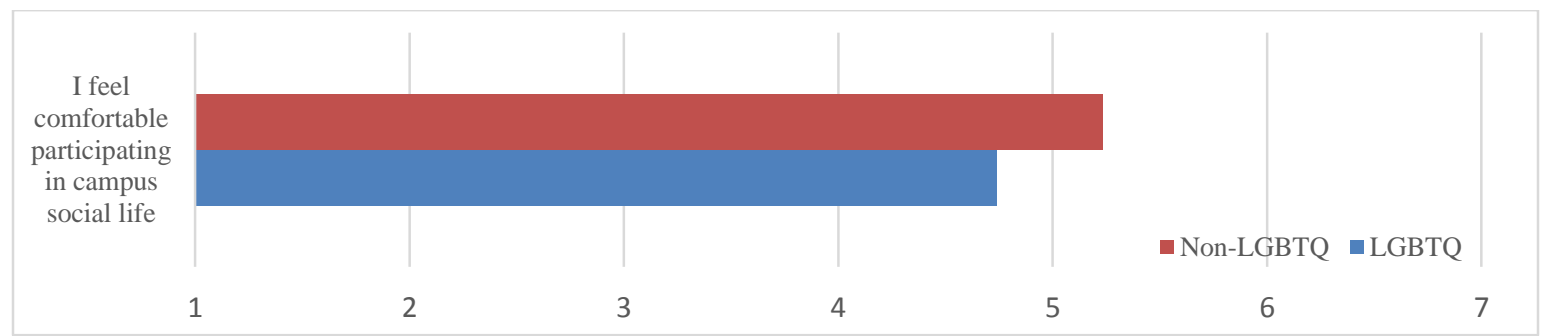


Regarding negative experiences on campus, LGBTQ students report having a wide range of such experiences more often. They report negative experiences from USM staff more often than their counterparts. These include hearing negative, inappropriate, or disparaging comments regarding gender $\left(t_{314}=3.54, p<.001, \omega^{2}=.04 ; Z=-4.27, p<.001\right)$, gender identity/expression $\left(t_{314}=4.34, p<.001, \omega^{2}=.05 ; Z=-4.63, p<.001\right)$, immigration status $\left(t_{314}=3.22, p=.001, \omega^{2}\right.$ $=.03 ; Z=-3.68, p<.001)$, psychological ability/disability $\left(t_{314}=3.11, p=.002, \omega^{2}=.03 ; Z=-\right.$ $3.47, p=.001)$, religious affiliation $\left(t_{313}=3.56, p<.001, \omega^{2}=.04 ; Z=-4.23, p<.001\right)$, sexual orientation $\left(t_{314}=4.39, p<.001, \omega^{2}=.06 ; Z=-4.67, p<.001\right)$, and socioeconomic status/income level $\left(t_{314}=3.23, p=.001, \omega^{2}=.03 ; Z=-4.33, p<.001\right)$. These differences are graphically depicted below.

Mean Scores for Disparaging Comments by Staff by Item by LGBTQ Grouping

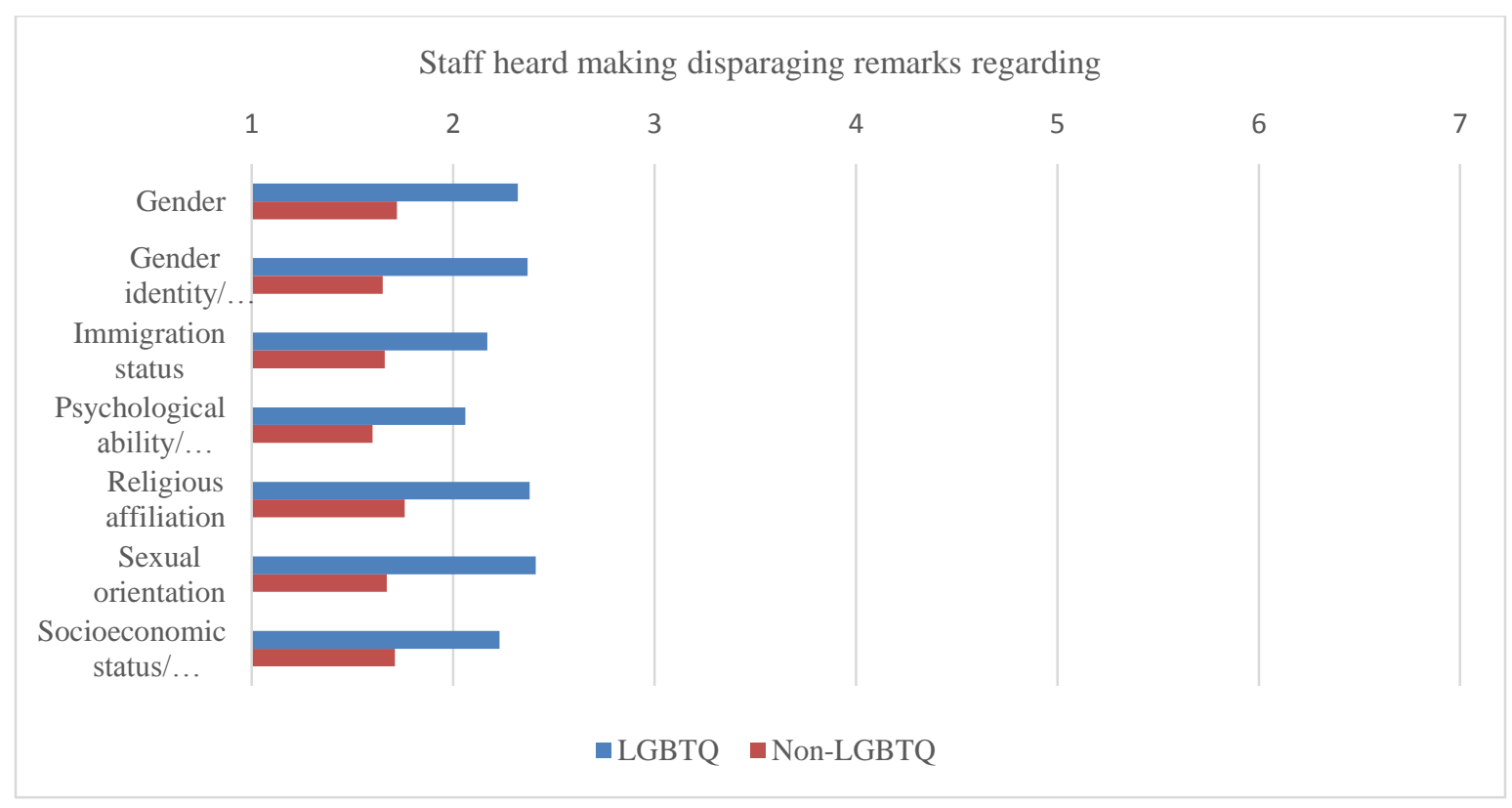

To understand how often students reported hearing disparaging remarks, we dichotomized the data by those who scored on the "often" end of the Likert-type scale, and those who were on the "not often" side of the scale. These are reported in the table below, with all percentages reflecting those who reported hearing the comments somewhat often or more. 
Percent Hearing Disparaging Remarks by Staff per Identity Category

\begin{tabular}{lrr}
\hline & LGBTQ & Non-LGTBQ \\
\hline Staff remarks about gender & $14.2 \%$ & $4.7 \%$ \\
Staff remarks about gender identity/expression & $13.3 \%$ & $3.8 \%$ \\
Staff remarks about gender & $7.5 \%$ & $3.2 \%$ \\
Staff remarks about psychological ability/disability & $7.5 \%$ & $3.0 \%$ \\
Staff remarks about religious affiliation & $11.7 \%$ & $6.6 \%$ \\
Staff remarks about sexual orientation & $13.3 \%$ & $4.7 \%$ \\
Staff remarks about socioeconomic status/income level & $10.0 \%$ & $4.3 \%$
\end{tabular}

This was mirrored in their experiences with campus administrators. LGBTQ students were more likely than their counterparts to report hearing campus administrators make negative, inappropriate, stereotypical, or disparaging comments regarding gender identity/expression $\left(t_{315}\right.$ $\left.=3.59, p<.001, \omega^{2}=.04 ; Z=-4.11, p<.001\right)$, and sexual orientation $\left(t_{316}=3.36, p=.001, \omega^{2}=\right.$ $.03 ; Z=-4.06, p<.001)$. These differences are depicted graphically below.

Mean Scores for Disparaging Comments by Administrators by Item by LGBTQ Grouping

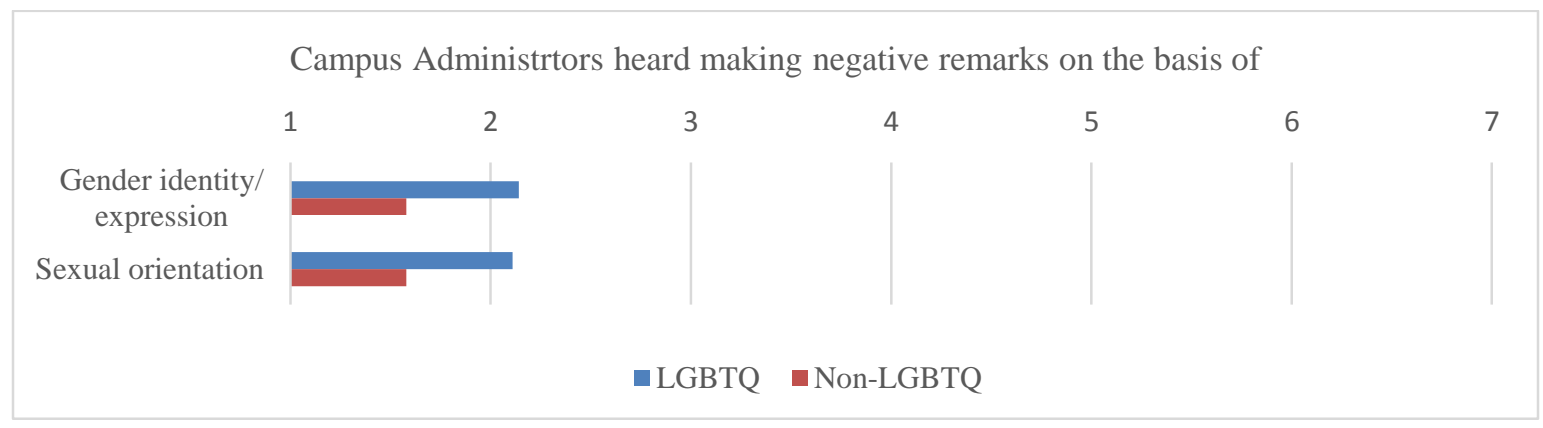

Again, to understand how often students reported hearing disparaging remarks, we dichotomized the data by those who scored on the "often" end of the Likert-type scale, and those who were on the "not often" side of the scale. These percentages are lower, which is perhaps not surprising given that students often interact less with administrators than with staff, and the question is about frequency (not a simple yes/no question). These are reported in the table below, with all percentages reflecting those who reported hearing the comments somewhat often or more. 
Percent Hearing Disparaging Remarks by Administrators per Identity Category

\begin{tabular}{lrr}
\hline & \multicolumn{1}{c}{ LGBTQ } & \multicolumn{1}{c}{ Non-LGTBQ } \\
\hline Administrator remarks about gender identity/expression & $2.3 \%$ & $1 \%$ \\
Administrator remarks about sexual orientation & $6.7 \%$ & $2.3 \%$ \\
\hline
\end{tabular}

In terms of experiences with students, a similar pattern emerged. LGBTQ students were more likely to report hearing other students make negative, inappropriate, stereotypical, or disparaging comments regarding age $\left(t_{317}=3.22, p=.001, \omega^{2}=.03 ; Z=-3.83, p<.001\right)$, ethnicity/race $\left(t_{317}=3.14, p=.002, \omega^{2}=.03 ; Z=-3.30, p=.001\right)$, gender $\left(t_{317}=4.23, p<.001\right.$, $\left.\omega^{2}=.05 ; Z=-4.68, p<.001\right)$, gender identity/expression $\left(t_{317}=5.09, p<.001, \omega^{2}=.07 ; Z=-\right.$ $5.46, p<.001)$, immigration status $\left(t_{317}=4.05, p<.001, \omega^{2}=.05 ; Z=-4.22, p<.001\right)$, learning ability/disability $\left(t_{316}=3.77, p<.001, \omega^{2}=.04 ; Z=-4.79, p<.001\right)$, psychological ability/disability $\left(t_{317}=4.47, p<.001, \omega^{2}=.06 ; Z=-5.06, p<.001\right)$, physical ability/disability $\left(t_{316}=3.237, p=.001, \omega^{2}=.03 ; Z=-4.22, p<.001\right)$, religious affiliation $\left(t_{316}=3.73, p<.001\right.$, $\left.\omega^{2}=.04 ; Z=-4.54, p<.001\right)$, and sexual orientation $\left(t_{317}=5.12, p<.001, \omega^{2}=.07 ; Z=-5.44, p\right.$ $<.001)$. These differences are graphically depicted below.

\section{Mean Scores on Disparaging Comments by Students by Item by LGBTQ Grouping}

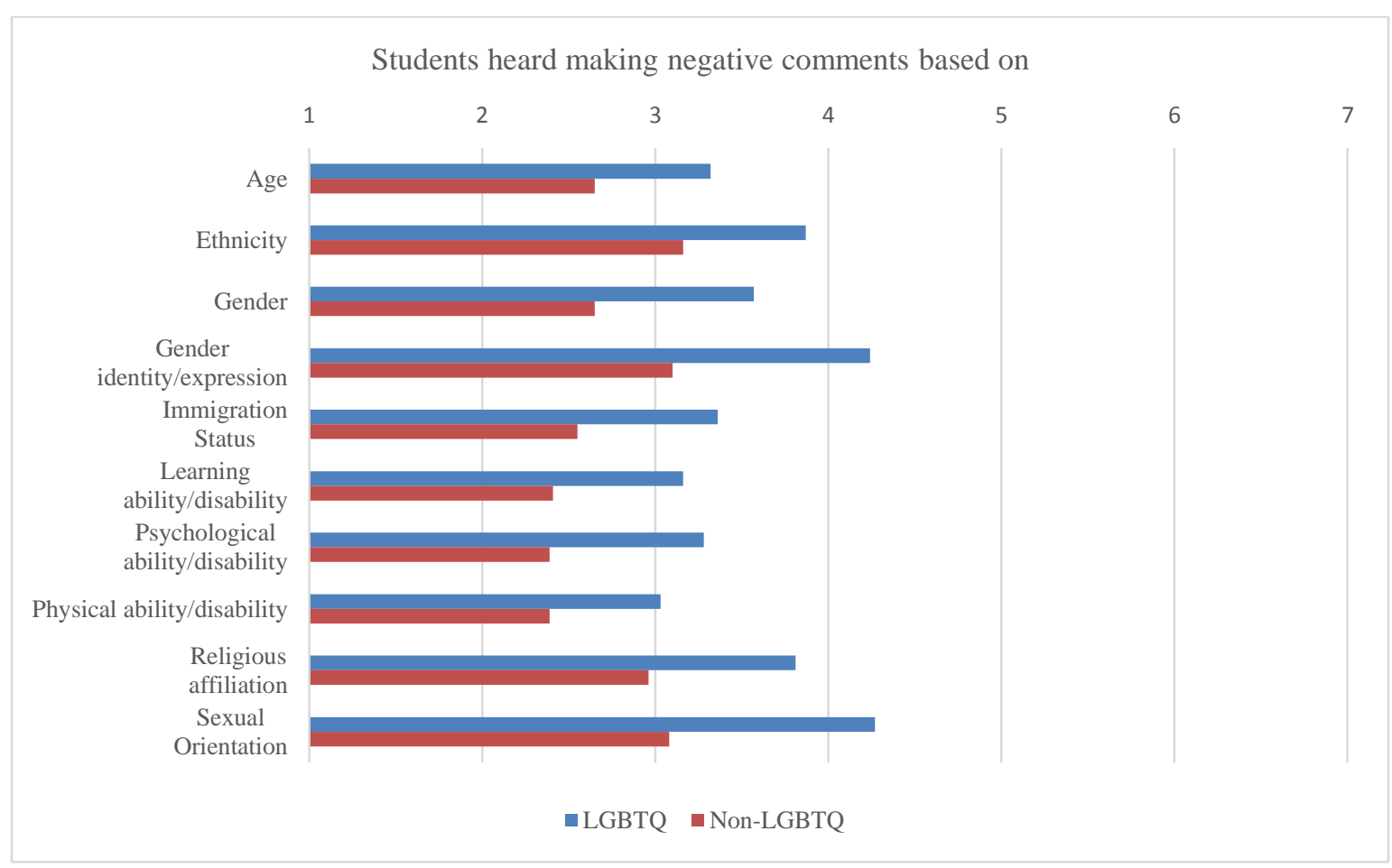


To understand how often students reported hearing disparaging remarks, we dichotomized the data by those who scored on the "often" end of the Likert-type scale, and those who were on the "not often" side of the scale. In this case, it should not be surprising that the relative percentages are much higher than for staff or administration, given that students come into contact with students at a much higher rate than they do with staff or administration. Thus, it is not surprising that given a question of frequency, they are likely to report more frequent comments from other students than they will from staff of administration. This comment is not meant to excuse these high numbers, simply to offer a potential explanation for the extreme differences between these percentages and those observed in the data about staff and administration. These are reported in the table below, with all percentages reflecting those who reported hearing the comments somewhat often or more.

Percent Hearing Disparaging Remarks by Students per Identity Category

\begin{tabular}{lcc}
\hline & LGBTQ & Non-LGTBQ \\
\hline Student remarks about age & $31.7 \%$ & $18.1 \%$ \\
Student remarks about ethnicity/race & $42.5 \%$ & $29.3 \%$ \\
Student remarks about gender & $37.5 \%$ & $16.7 \%$ \\
Student remarks about gender identity/expression & $48.3 \%$ & $16.7 \%$ \\
Student remarks about immigration status & $27.5 \%$ & $14.4 \%$ \\
Student remarks about learning ability/disability & $22.5 \%$ & $11.7 \%$ \\
Student remarks about psychological ability/disability & $25.8 \%$ & $12.5 \%$ \\
Student remarks about physical ability/disability & $20.0 \%$ & $11.2 \%$ \\
Student remarks about religious affiliation & $41.7 \%$ & $22.4 \%$ \\
Student remarks about sexual orientation & $50.8 \%$ & $28.4 \%$ \\
\hline
\end{tabular}

Finally, LGBTQ students were more likely than their counterparts to hear such comments in campus housing $\left(t_{314}=3.19, p=.002, \omega^{2}=.03 ; Z=-3.16, p=.002\right)$ and campus dining facilities $\left(t_{314}=3.26, p=.001, \omega^{2}=.03 ; Z=-3.06, p=.002\right)$. These differences are graphically depicted below. 
Mean Scores on Frequency Negative Comments Heard by Location by LGBTQ Grouping

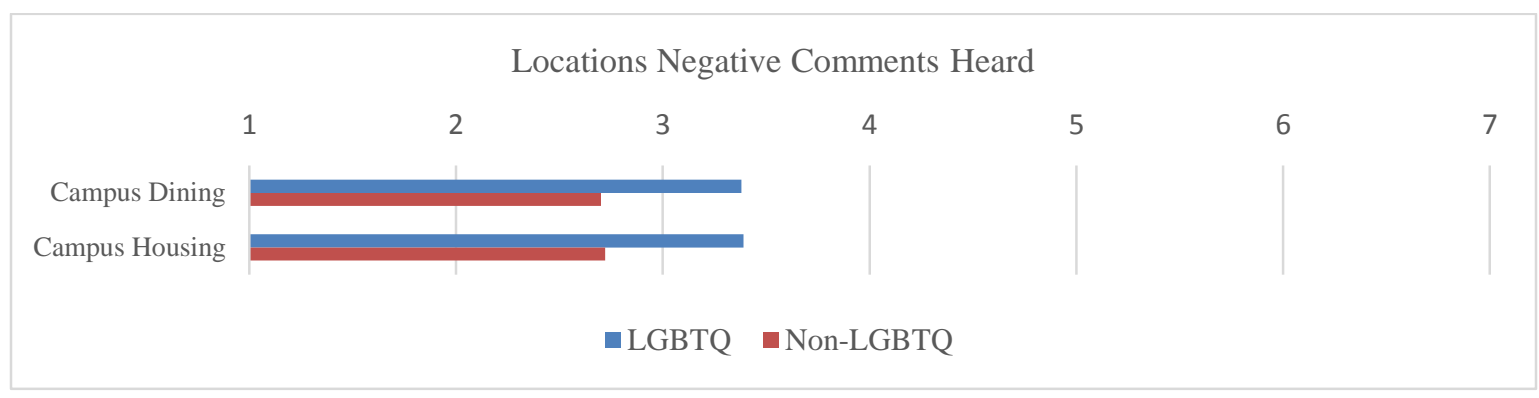

In terms of threatening behaviors on campus, LGBTQ students were more likely than their counterparts to report witnessing threatening behavior on the basis of country of origin ( $t_{317}$ $\left.=3.50, p=.001, \omega^{2}=.03 ; Z=-3.67, p<.001\right)$, English language proficiency $\left(t_{317}=3.59, p<\right.$ $\left..001, \omega^{2}=.04 ; Z=-4.21, p<.001\right)$, ethnicity/race $\left(t_{317}=3.85, p<.001, \omega^{2}=.04 ; Z=-3.64, p<\right.$ $.001)$, gender $\left(t_{317}=4.27, p<.001, \omega^{2}=.05 ; Z=-4.47, p<.001\right)$, gender identity/expression $\left(t_{316}\right.$ $\left.=5.11, p<.001, \omega^{2}=.07 ; Z=-4.80, p<.001\right)$, immigration status $\left(t_{317}=3.60, p<.001, \omega^{2}=\right.$ $.04 ; Z=-4.17, p<.001)$, learning ability/disability $\left(t_{317}=4.08, p<.001, \omega^{2}=.05 ; Z=-4.61, p<\right.$ $.001)$, psychological ability/disability $\left(t_{317}=4.14, p<.001, \omega^{2}=.05 ; Z=-4.67, p<.001\right)$, physical ability/disability $\left(t_{317}=3.40, p=.001, \omega^{2}=.03 ; Z=-4.25, p<.001\right)$, religious affiliation $\left(t_{317}=4.07, p<.001, \omega^{2}=.05 ; Z=-4.56, p<.001\right)$, sexual orientation $(t 317=5.36, p$ $\left.<.001, \omega^{2}=.08 ; Z=-5.20, p<.001\right)$, and socioeconomic status/income level $\left(t_{317}=3.87, p<\right.$ $\left..001, \omega^{2}=.04 ; Z=-4.23, p<.001\right)$. The differences are graphically depicted below. The results on these items may be particularly troubling because $21.5 \%(n=249)$ of those responding (all students combined) report witnessing threatening behavior on the basis of sexual orientation at least somewhat often on campus. Further, 19.4\% $(n=229)$ of the total sample report witnessing threatening behavior on the basis of gender identity/expression at least somewhat often on campus. 
Mean Scores on Threatening Behavior by Item by LGBTQ Grouping

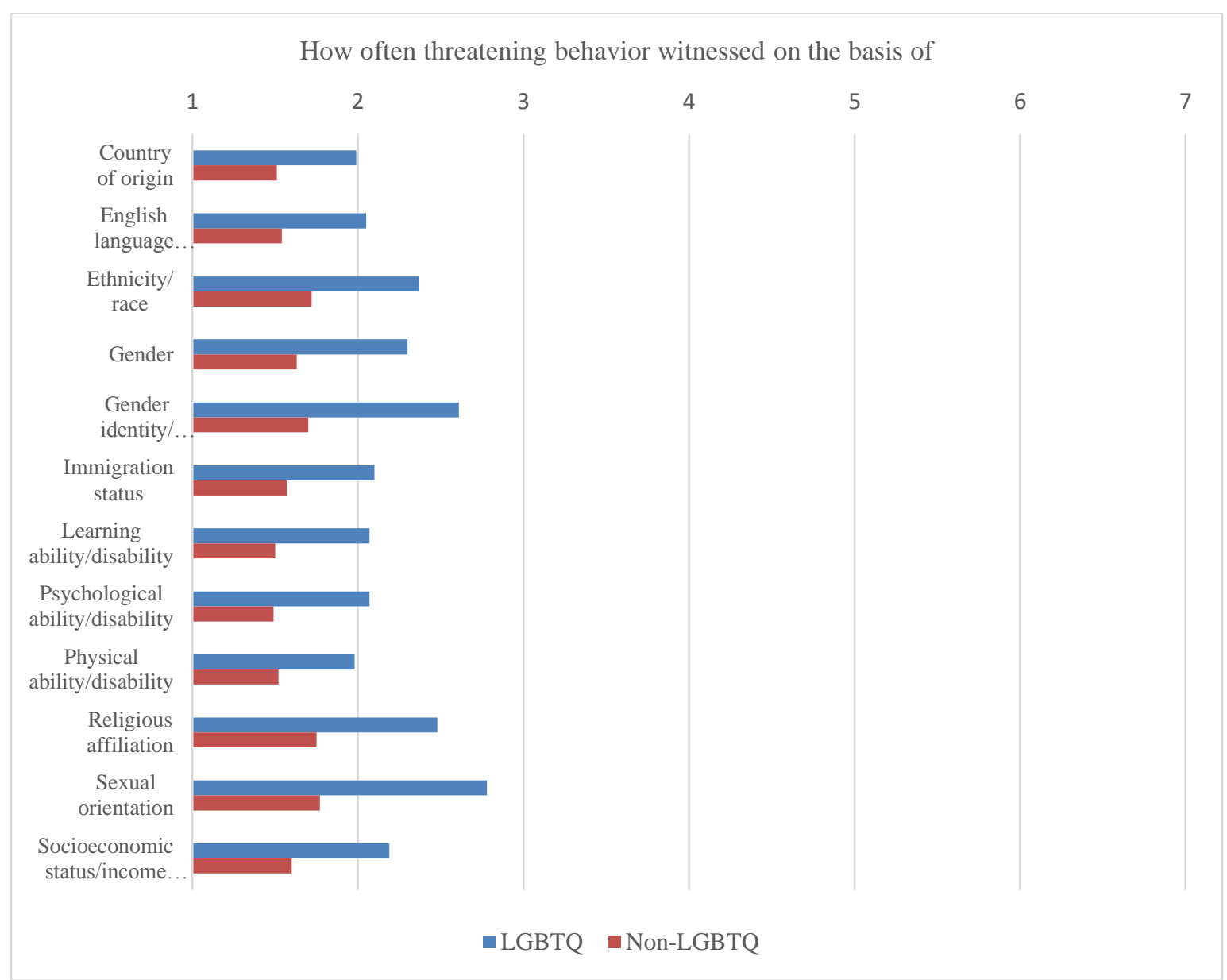

As with the earlier data, to understand how often students reported witnessing threatening behavior, we dichotomized the data by those who scored on the "often" end of the Likert-type scale, and those who were on the "not often" side of the scale. These are reported in the table below, with all percentages reflecting those who reported hearing the comments somewhat often or more. 
Percent Witnessing Threatening Behavior Often per Identity Category

\begin{tabular}{lrr}
\hline & LGBTQ & Non-LGTBQ \\
\hline Threatening behavior on the basis of country of origin & $4.2 \%$ & $2.4 \%$ \\
Threatening behavior on the basis of English language proficiency & $4.2 \%$ & $2.7 \%$ \\
Threatening behavior on the basis of ethnicity/race & $12.5 \%$ & $7.1 \%$ \\
Threatening behavior on the basis of gender & $10.8 \%$ & $4.8 \%$ \\
Threatening behavior on the basis of gender identity/expression & $17.5 \%$ & $6.1 \%$ \\
Threatening behavior on the basis of immigration status & $4.2 \%$ & $2.4 \%$ \\
Threatening behavior on the basis of learning ability/disability & $5.8 \%$ & $1.9 \%$ \\
Threatening behavior on the basis of psychological ability/disability & $5.0 \%$ & $2.1 \%$ \\
Threatening behavior on the basis of physical ability/disability & $2.5 \%$ & $2.0 \%$ \\
Threatening behavior on the basis of religious affiliation & $12.5 \%$ & $6.8 \%$ \\
Threatening behavior on the basis of sexual orientation & $22.5 \%$ & $7.8 \%$ \\
Threatening behavior on the basis of socioeconomic status/income & $6.7 \%$ & $4.0 \%$ \\
\hline
\end{tabular}

\section{LGBTQ Students' Views about Campus}

LGBTQ students were less likely to agree that USM had made an inclusive campus community a priority, with $39.2 \%$ of LGBTQ students on the disagree side of the rating scale, versus $23.2 \%$ of their counterparts $\left(t_{317}=-3.66, p<.001, \omega^{2}=.04 ; Z=-4.06, p<.001\right)$. This item mirrored that of whether USM articulates values of diversity and inclusion, on which LGBTQ students were less likely to agree (40\% disagreed) than their counterparts (24.3\% disagree; $\left.t_{317}=-3.64, p<.001, \omega^{2}=.04 ; Z=-4.34, p<.001\right)$. LGBTQ students also responded more negatively to whether they received a consistent message from USM about inclusion and diversity $\left(t_{319}=-3.48, p=.001, \omega^{2}=.03 ; Z=-3.83, p<.001\right)$. On that item, $40 \%$ of LGBTQ students disagreed, compared with $21.7 \%$ of their counterparts. This is again mirrored in whether USM is a good place to gain an understanding of multicultural and diversity issues, with LGBTQ students more apt to disagree $\left(t_{318}=-3.60, p<.001, \omega^{2}=.04 ; Z=-4.25, p<.001\right)$. Among LGBTQ students, $43.3 \%$ disagreed, versus $24.4 \%$ of their counterparts. Means for these items are graphically displayed below. 


\section{Mean Scores for Perception of Campus by Item by LGBTQ Grouping}

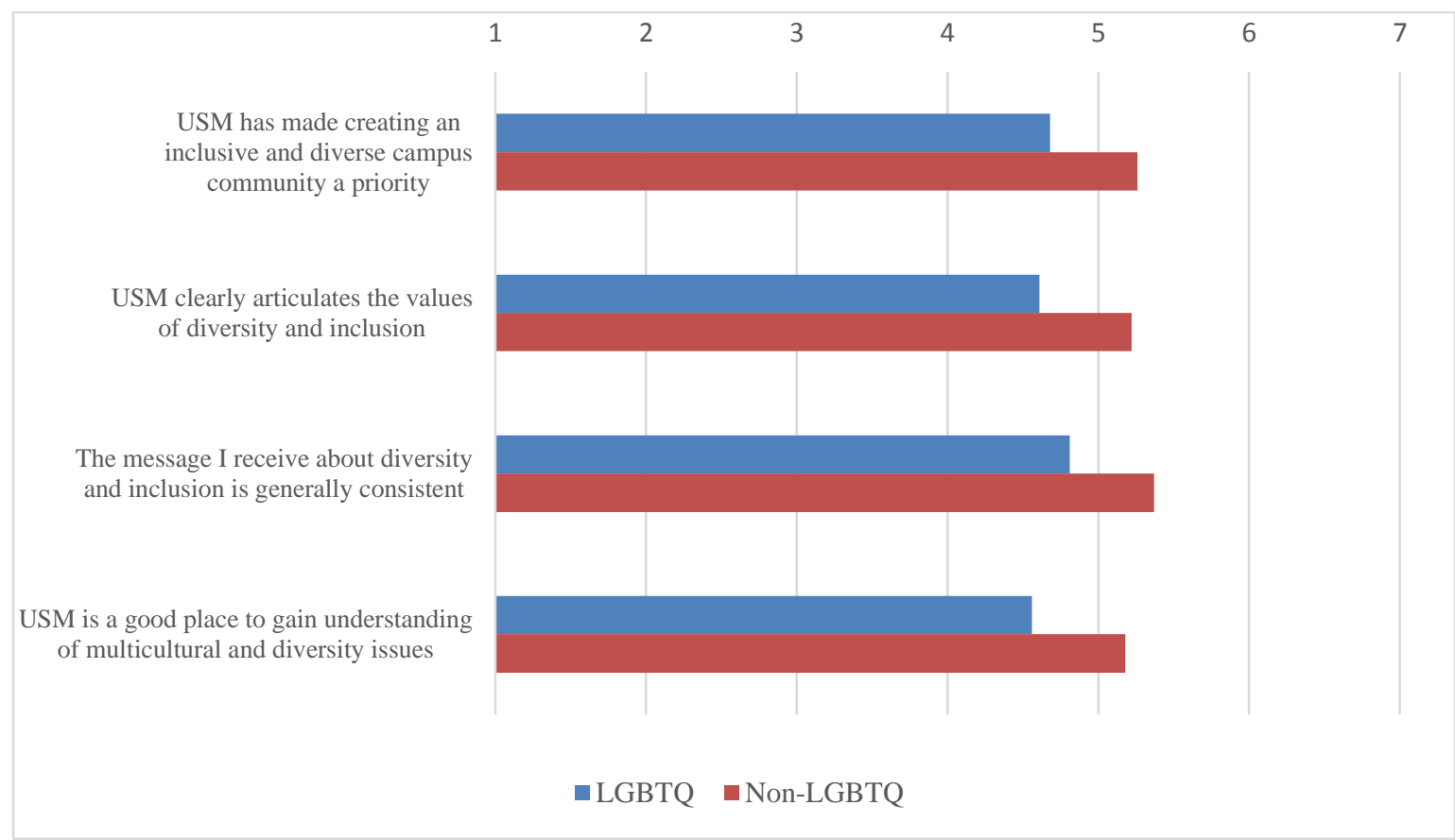

These results are perhaps best contextualized within the results of another item. Overall, 39.4\% of students rated on the "agree" end of the scale on whether a diverse and inclusive campus environment played a role in their decision of which university to attend $(M=3.95, S D=1.92)$. In other words, almost 4 out of 10 students considered the diversity and inclusiveness of a campus environment prior to attending USM, making the gap on these items a recruitment and retention issue.

In general, LGBTQ students seemed to view the USM campus as a less supportive environment for a range of students, including themselves. They rated USM as significantly less supportive than their counterparts for students on the basis of ethnicity/race $\left(t_{319}=-3.29, p=\right.$ $\left..001, \omega^{2}=.03 ; Z=-3.62, p<.001\right)$, gender identity/expression $\left(t_{316}=-5.22, p<.001, \omega^{2}=.08 ; Z\right.$ $=-5.06, p<.001)$, immigration status $\left(t_{317}=-3.49, p=.001, \omega^{2}=.03 ; Z=-3.34\right.$, $p=.001)$, learning ability/disability $\left(t_{317}=-3.47, p=.001, \omega^{2}=.03 ; Z=-4.14, p<.001\right)$, physical ability/disability $\left(t_{316}=-4.20, p<.001, \omega^{2}=.05 ; Z=-4.81, p<.001\right)$, religious affiliation $\left(t_{316}=-3.61, p<.001, \omega^{2}=.04 ; Z=-4.43, p<.001\right)$, and sexual orientation $\left(t_{317}=-\right.$ $\left.4.76, p<.001, \omega^{2}=.06 ; Z=-4.71, p<.001\right)$. A graphical depiction of these differences is below. 
Mean Scores of USM as Supportive by Item by LGBTQ Grouping

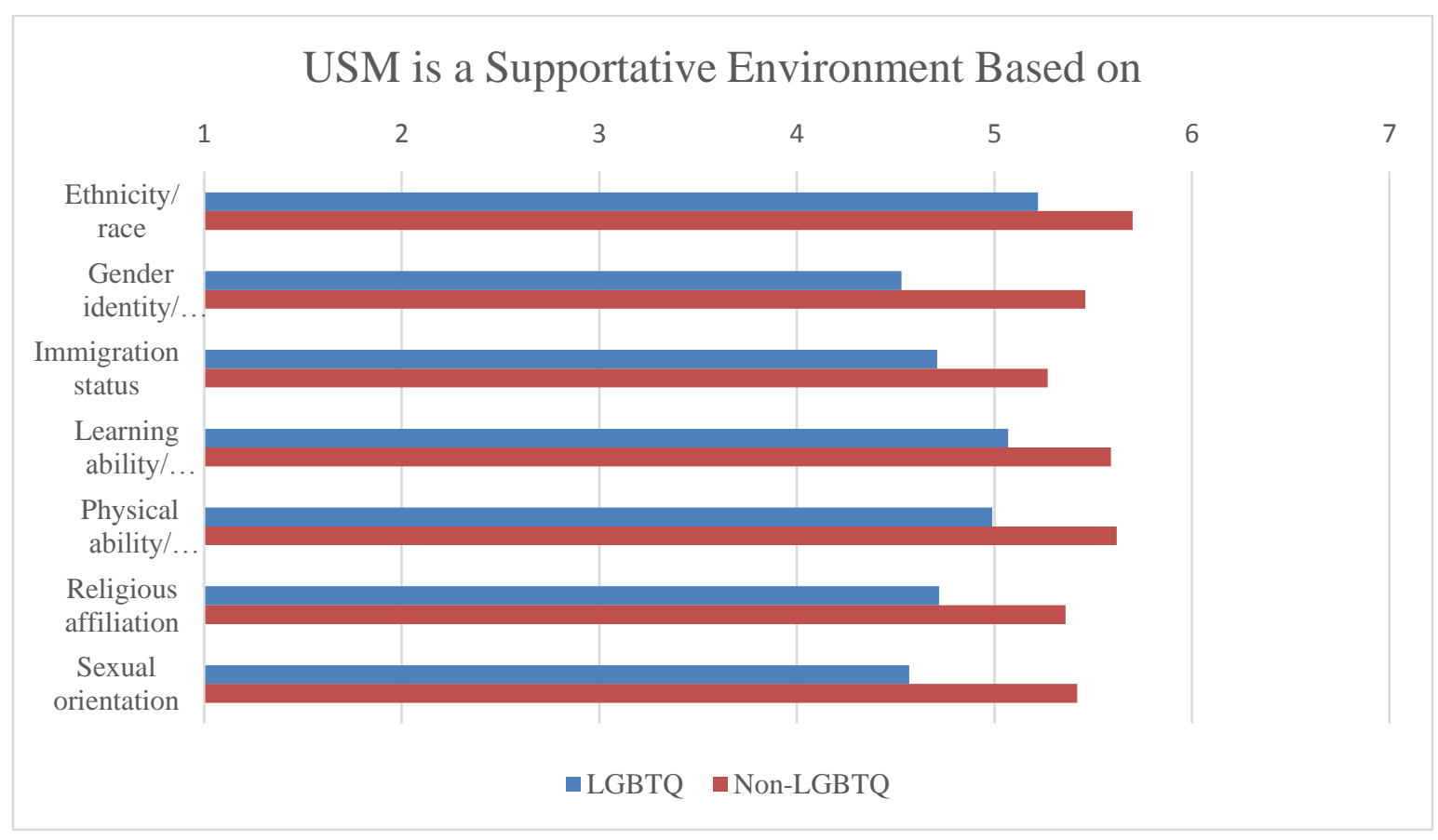

As with the data on on-campus experiences, to understand how often students reported hearing disparaging remarks, we dichotomized the data by those who scored on the "disagree" end of the Likert-type scale, and those who were on the "agree" side of the scale. These are reported in the table below, with all percentages reflecting those who rated "somewhat disagree" or lower on the item.

\section{Percent Disagreeing Whether USM is Supportive per Identity Category}

\begin{tabular}{lrr}
\hline & LGBTQ & Non-LGTBQ \\
\hline Supportive on the basis of ethnicity/race & $25.8 \%$ & $17.0 \%$ \\
Supportive on the basis of gender identity/expression & $48.3 \%$ & $26.1 \%$ \\
Supportive on the basis of immigration status & $50.0 \%$ & $35.7 \%$ \\
Supportive on the basis of learning ability/disability & $33.3 \%$ & $21.8 \%$ \\
Supportive on the basis of physical ability/disability & $39.2 \%$ & $21.1 \%$ \\
Supportive on the basis of religious affiliation & $41.7 \%$ & $24.7 \%$ \\
Supportive on the basis of sexual orientation & $44.2 \%$ & $26.1 \%$ \\
\hline
\end{tabular}




\section{Comparative Data}

In order to give context to the USM data, we also wish to allow comparison to regional and national data from similar items on other campus climate surveys as they relate to LGBTQ students. We have sampled from 20 universities, including 10 in the Gulf South region, and 10 outside of that region. It is worth noting that other universities' data do not always contain comparable items, so not all are included in every comparison. However, we selected five items for comparison that were common to many of the surveys at other universities. For the sake of comparison, we here provide percentage statistics for the USM data alongside the regional and national comparison groups.

\section{Comparison to Other Universities in the Region and Nation}

\begin{tabular}{lrrr}
\hline & USM & Regional & National \\
\hline Campus is supportive for LGBTQ students (\% disagree) & $44.2 \%$ & $22.8 \%$ & $24.7 \%$ \\
Negative behavior on the basis of gender identity (\% often) & $17.5 \%$ & $18.3 \%$ & $16.3 \%$ \\
Negative behavior on the basis of sexual orientation (\% often) & $22.5 \%$ & $29.1 \%$ & $20.4 \%$ \\
Disparaging staff comments on sexual orientation (\% often) & $13.3 \%$ & $4.0 \%$ & $3.8 \%$ \\
Disparaging student comments on sexual orientation (\% often) & $50.8 \%$ & $36.8 \%$ & $36.7 \%$
\end{tabular}

Note. The percentages reported for the regional and national comparison groups are actually mean percentages of all universities in the group.

In all cases, the differences between the comparison items were tested using the chisquare goodness of fit test. The USM distribution is significantly different from the regional comparison group $\left(\chi_{4}^{2}=784.65, p<.001\right)$. The USM group was higher in the percent disagreeing that the campus is supportive for LGBTQ students $(S R=4.48)$, the percent hearing disparaging comments from staff on sexual orientation $(S R=4.65)$, and the percent hearing disparaging comments from students $(S R=2.31)$. The USM distribution was also significantly different from the national comparison group $\left(\chi^{2}{ }_{4}=677.11, p<.001\right)$. Again in this case, the USM group was higher in the percent disagreeing that the campus is supportive for LGBTQ students $(S R=3.94)$, the percent hearing disparaging comments from staff on sexual orientation $(S R=4.87)$, and the percent hearing disparaging comments from students $(S R=2.33)$.

For the purposes of context, we also compared the regional and the national comparison groups to one another, to determine how different the Gulf South universities may be from the 
national comparison group. This was done in order to understand how far apart the USM scores might be from the norm. There were no significant differences between the regional and national comparison groups $(p>.05)$. This suggests that the Gulf South region does not significantly differ from the rest of the nation on these items, but that USM significantly deviates from both the region and the nation.

\section{Discussion of Results}

The results indicate a wide array of ways in which LGBTQ students find the USM campus unsupportive and, in some cases, might experience it as hostile (i.e., they are more likely to experience assault and harassment on campus than are others). We elected to pursue a comparative strategy in this analysis out of the feeling that allowing the predominant group to assess whether a potentially marginalized group was being supported was ineffective. Those subject to bias, discrimination, and negative on-campus experiences are most likely to be able to report them. So, we chose to center the experiences of LGBTQ students in this analysis by highlighting how their perceptions and reported experiences are different from their counterparts. What emerges is a clear picture: On average, LGBTQ students view the campus as less supportive, employees and students as more likely to make negative comments or enact threatening behavior, and the administration as less interested in diversity and inclusiveness. Not only that, but USM students rate their campus as more hostile for LGBTQ students than those at comparison Gulf South universities, and at other comparison universities nationally. Given that close to $40 \%$ of the USM students sampled agreed that diversity and inclusion are part of the decision in which college to attend, these finding present a challenge and an opportunity. The challenge is obvious - USM must become a more supportive environment for LGBTQ students, staff, and faculty. This is a challenge because it must be accomplished in a political and cultural atmosphere that is not always amenable to such inclusiveness, and because creating services may involve expense. But it is an opportunity because of the ways in which a diverse, inclusive environment benefits all students, and the potential link to retention and recruitment demonstrated by these data.

USM does some things currently, and is working to improve on those assets. For example, an Allies/safe space training already exists, and is currently in the process of being improved, revised, and expanded. However, no LGBTQ resource center exists on campus. Student groups that do exist (i.e. the Gay Straight Alliance, and the Alliance for Equality) could 
be more effective with more support and visibility. This is based on several students mentioning in the open-ended data that they wished USM had a GSA, and that they would attend if one existed. Although residence life staff mention there is a way of working with trans* students, no written trans* inclusive housing policy can be found on the USM website. Creating such a policy, and housing it in a website that is easily found and used by current and prospective LGBTQ students would be a positive step. LGBTQ scholarships have been created on the Coast campus, but not yet in Hattiesburg. Gender-inclusive bathrooms are rare on either campus. Students are not, at present, required to undergo any education regarding issues of sexual orientation or gender diversity. Neither are faculty or staff. There are a number of simple, straightforward steps that might greatly benefit the campus climate for LGBTQ students, and ultimately help position the university more competitively to recruit and retain these students, who make up $9 \%$ of the student body, at least in the present sample. 


\section{References}

Aragon, S. R., Poteat, V. P., Espelage, D. L., \& Koenig, B. W. (2014). The influence of peer victimization on educational outcomes for LGBTQ and non-LGBTQ high school students. Journal of LGBT Youth, 11(1), 1-19.

Doyle, D. M., \& Molix, L. (2014). Perceived discrimination and well-being in gay men: The protective role of behavioural identification. Psychology and Sexuality, 5(2), 117-130.

Espelage, D. L., Aragon, S. R., Birkett, M., \& Koenig, B. W. (2008). Homophobic teasing, psychological outcomes, and sexual orientation among high school students: What influence do parents and schools have? School psychology review, 37(2), 202-216.

Ferfolja, T. (2007). Schooling cultures: Institutionalizing heteronormativity and heterosexism. International Journal of Inclusive Education, 11(2), 147-162.

GLSEN (2011). The 2011 school climate survey: The experiences of lesbian, gay, bisexual, and transgender youth in our nation's schools. Report of the Gay, Lesbian, and Straight Education Network. Retrieved from http://files.eric.ed.gov/fulltext/ED535177.pdf

Human Rights Campaign (2014). This is our home. Report on 2014 survey of LGBT Mississippians. Retrieved from http://hrc-assets.s3-website-us-east1.amazonaws.com//files/assets/resources/HRC_ProjectOneAmerica_MS.pdf

Hylton, M. E. (2006). Queer in southern MSW programs: Lesbian and bisexual women discuss stigma management. The Journal of Social Psychology, 146(5), 611-628.

Irwin, J. A., \& Austin, E. L. (2013). Suicide ideation and suicide attempts among white Southern lesbians. Journal of Gay and Lesbian Mental Health, 17(1), 4-20.

Klawitter, M. (2011). Multilevel analysis of the effects of antidiscrimination policies on earnings by social orientation. Journal of Policy Analysis and Management, 30(2), 334-358.

Kosciw, J. G., Palmer, N. A., Kull, R. M., \& Greytak, E. A. (2013). The effect of negative school climate on academic outcomes for LGBT youth and the role of in-school supports. Journal of School Violence, 12(1), 45-63.

McGuire, J.K., Anderson, C. R., Toomey, R. B., \& Russell, S. T. (2010). School climate for transgender youth: A mixed method investigation of student experiences and school reponses. Journal of Youth and Adolescence, 10, 1175-1188.

Morman, M., Schrodt, P., \& Tornes, M. J. (2013). Self-disclosure mediates the effects of gender orientation and homophobia on the relationship quality of male same-sex friendships. Journal of Social and Personal Relationships, 30(5), 582-605.

Norris, W. P. (1992). Liberal attitudes and homophobic acts: The paradoxes of homosexual experience in a liberal institution. Journal of Homosexuality, 22(3-4), 81-87.

Rankin, S., Weber, G., Blumenfeld, W., \& Frazer, S. (2010). State of higher education for lesbian, gay, bisexual, and transgender people. Charlotte, NC: Campus Pride.

Russell, S. T., Ryan, C., Toomey, R. B., Diaz, R. M., Sanchez, J. (2011). Lesbian, gay, bisexual, and transgender adolescent school victimization: Implications for young adult health and adjustment. Journal of School Health, 81(5), 223-230.

Strunk, K. K., \& Bailey, L. E. (2014). The difference one word makes: Imagining sexual orientation in graduate school application essays. Manuscript submitted for publication.

Swank, E., Frost, D. M., \& Fahs, B. (2012). Rural location and exposure to minority stress among sexual minorities in the United States. Psychology and Sexuality, 3(2), 226-243. 